\title{
Structural Analysis of Backfill Highway Subgrade on the Lower Bearing Capacity Foundation Using the Finite Element Method
}

\author{
Wenjuan Xu, ${ }^{1,2}$ Xin Huang, ${ }^{1}$ Jiandong Huang $\mathbb{C}^{3},{ }^{3}$ and Zhengjun Yang ${ }^{1,4}$ \\ ${ }^{1}$ College of Civil Engineering, Nanjing Forestry University, Nanjing 210037, China \\ ${ }^{2}$ Jiangsu Agricultural and Forestry Technical College, Zhenjiang 212400, China \\ ${ }^{3}$ School of Mines, China University of Mining and Technology, Xuzhou 221116, China \\ ${ }^{4} J u r o n g$ Traffic and Transport Bureau, Zhenjiang 212400, China \\ Correspondence should be addressed to Jiandong Huang; huang@cumt.edu.cn
}

Received 10 September 2021; Revised 22 October 2021; Accepted 25 October 2021; Published 8 November 2021

Academic Editor: Wenjie Ge

Copyright ( $\odot 2021$ Wenjuan Xu et al. This is an open access article distributed under the Creative Commons Attribution License, which permits unrestricted use, distribution, and reproduction in any medium, provided the original work is properly cited.

\begin{abstract}
The present study is to investigate the stability of the backfill subgrade on the lower bearing capacity foundation. A finite element (FE) model was constructed to simulate the high-filled road subjected to the actual self-weight load. The strength reduction method was adopted to establish an analysis model of slope stability. At the same time, the sensitivity analysis of the factors affecting the slope stability was carried out through parametric studies, including the elastic modulus, cohesion, internal friction angle, and slope rate. The results showed that the slope stability analysis model established by the strength reduction method can characterize the stability of the slope by calculating the slope safety coefficient. The mutation point of the relationship curve between the displacement generated in the slope and the reduction coefficient can be used as the criterion. Under the condition of a given strength reduction coefficient, the calculated results obtained through FE modeling can show the development of the equivalent plastic zone in the form of cloud diagrams.
\end{abstract}

\section{Introduction}

Road slope refers to the infrastructure constructed or modified to meet the needs of road construction [1-5]. The slope formed under certain conditions (topography and geology) will break the previous mechanical balance into an unstable body due to changes in external factors. Under the action of its own weight or other loads, it will follow a certain relatively weak surface $[4,6,7]$. A landslide is a kind of bad geological phenomenon such as sliding downwards as a whole, intermittently slowly, and sometimes even suddenly. The factors that cause landslides include excavation of side slopes, rapid embankment filling, earthquakes, river erosion, sudden drops in reservoir water levels, and heavy rains $[6,8-10]$. The slope is not only a special geological environment but also an important part of engineering construction. Due to the construction demand for a large number of highway projects in recent years, the stability of the slope during the construction process is a link that cannot be ignored [11-14].
In the past, there were various approximate methods and specialized methods, which can be used to calculate the global safety factor that depends on the slope height, the steepness, and the constitutive properties of the soil constituting the slope. Nash [15] conducted a comprehensive review of many classic slope stability analysis methods. The limitation of many of these classical methods is that Mohr-Coulomb shear strength behavior with a fixed friction angle is usually assumed because of the inherent application of simple statistical methods to the soil. Approximately, the calculation of stress and related shear strength is a continuous mechanical problem with static uncertainties [16-18]. To reduce manual trials and errors associated with these technologies, such as slicing methods, many engineering software packages have been developed, but most software packages still use simple static methods to approximate soil stress and strength [19-22].

In the FE analysis, the method of increasing the external load or reducing the material strength of the rock- 
soil mass is the earlier method adopted [23, 24]. The stability analysis of these slopes mainly includes the judgment basis of slope instability, the stability of the excavated slope, the comparative analysis of the selection of different software, and the analysis of the internal force of the slope with the supporting structure $[25,26]$. In recent years, the FE method has been increasingly used to predict the displacement and stress in statically indeterminate slopes, dams, and embankments [5, 13, 14, 27-45]. The potential attractiveness of calculating slope stability in a continuum/finite element framework lies in many previous studies [7]. The equilibrium stress, strain, and related shear strength in the soil have been calculated accurately in the studies conducted by Aryal and Duncan $[41,44]$. The general material models of soil (including Mohr-Coulomb and many other models) have been employed in the studies conducted by Ardah et al. [46]. The FEM method has been applied in $2 \mathrm{D}$ or $3 \mathrm{D}$ with complex slope combinations and soil sediments to model almost all types of mechanisms [47]. The FEM method has also been extended to address the damage caused by leakage, brittle soil behavior, random "yield soil" properties, and interventions such as engineering geotextiles, soil nails, drainage ditches, and retaining walls $[5,38,40,42-45]$. To fully understand the stability condition of the backfill soil on the high-filled road with lower foundation bearing capacity, this article adopts the classic slope stability analysis method. In this method, the inclined soil is subjected to the actual self-weight load, and the purpose is to find a continuous surface through the soil that has the smallest safety coefficient against the slip or shear failure. The safety coefficient is defined as the degree to which the shear strength of the soil is reduced so that the slope has just reached the critical failure state.

\section{Research Objective and Overview}

The present study is to investigate the stability condition of the backfill soil on the high-filled road with lower foundation bearing capacity, as shown in Figure 1. A FE model was constructed to simulate the high-filled road subjected to the actual self-weight load. The strength reduction method was adopted to establish an analysis model of slope stability. At the same time, the sensitivity analysis of the factors affecting the slope stability was carried out through parametric studies, including the elastic modulus, cohesion, internal friction angle, and slope rate. Under the condition of a given strength reduction coefficient, the simulation results obtained by ABAQUS software show the development of the equivalent plastic zone in the way of cloud maps. The slope is stable under the reduction factor when the failure of transfixion or local yield failure occurs. If the reduction coefficient continues to increase, the slope is in a critical failure state when the plastic strain between adjacent iterative steps increases too much or the equivalent plastic strain reaches the yield limit at some nodes, and the strength reduction coefficient is positioned as the minimum safety factor of the overall stability of the slope.

\section{Model Construction}

In the present study, the FE method was adopted. In this method, a structure is regarded as a whole composed of a finite number of elements through nodes [5, 14, 30]. Except for the nodes which are fixed on the boundary, the displacement of each node that can produce displacement can be calculated by using equilibrium conditions, and then the internal forces of each element can be calculated by the node displacement [33-35].

In the finite element analysis of the strength reduction of the slope, the stability of the slope usually adopts the nonconvergence of the solution as the failure criterion [48]. Within the maximum number of iterations, if the calculation fails to converge, it means that no stress distribution that can satisfy both the failure criterion and the overall balance is found, which means that the soil has been damaged. Specifically, the actual strength parameters $c^{\prime}$ and $\varphi^{\prime}$ of the backfilled roadbed are divided by a reduction factor $F_{\text {trial }}$ at the same time to obtain a set of new values of $c^{\prime \prime}$ and $\varphi^{\prime \prime}$ after reduction, i.e.,

$$
\left\{\begin{array}{l}
c^{\prime \prime}=\frac{c^{\prime}}{F_{\text {trial }}}, \\
\varphi^{\prime \prime}=\arctan \left|\frac{1}{F_{\text {trial }}} \tan \varphi^{\prime}\right| .
\end{array}\right.
$$

Then, the reduced values of $c^{\prime \prime}$ and $\varphi^{\prime \prime}$ are taken into the trial calculation of finite elements as new material parameters $[49,50]$. When the finite element calculation converges, the value of $F_{\text {trial }}$ is slightly larger, and then the trial calculation is carried out until the finite element no longer converges, which indicates that the soil reaches the critical limit state and the slope shear failure occurs. At this time, the critical slip surface and safety factors are obtained.

The gravity load is determined by the following method $[51,52]$. On each one of the finite elements, the gravitational load generated by the weight of the soil can be obtained by the following equation:

$$
p^{(e)}=\Upsilon \int S^{e N^{T}} \mathrm{~d} S
$$

in which $S$ is the area of the element; $e$ is the element number. The result of this integration is to take the product of the area of each element and the weight of the soil as the element's gravity load and then distribute it to each node. Various complex constitutive models can be considered in the FE analysis, but the most common in engineering analysis is the ideal elastoplastic model because the results of the ideal elastoplastic model are the most comparable to the results of the limit equilibrium method. For general road slopes, the shear failure of the soil is mainly controlled, and the calculation accuracy of the distribution and size of the plastic zone is relatively high, and the requirements for the displacement are relatively low.

In the present study, the Mohr-Coulomb plastic model was employed to characterize the constitutive property of the soil. The yield criterion of the Mohr-Coulomb model is assumed as follows. When the shear stress acting on a certain point is equal to the shear strength of that point, the point 


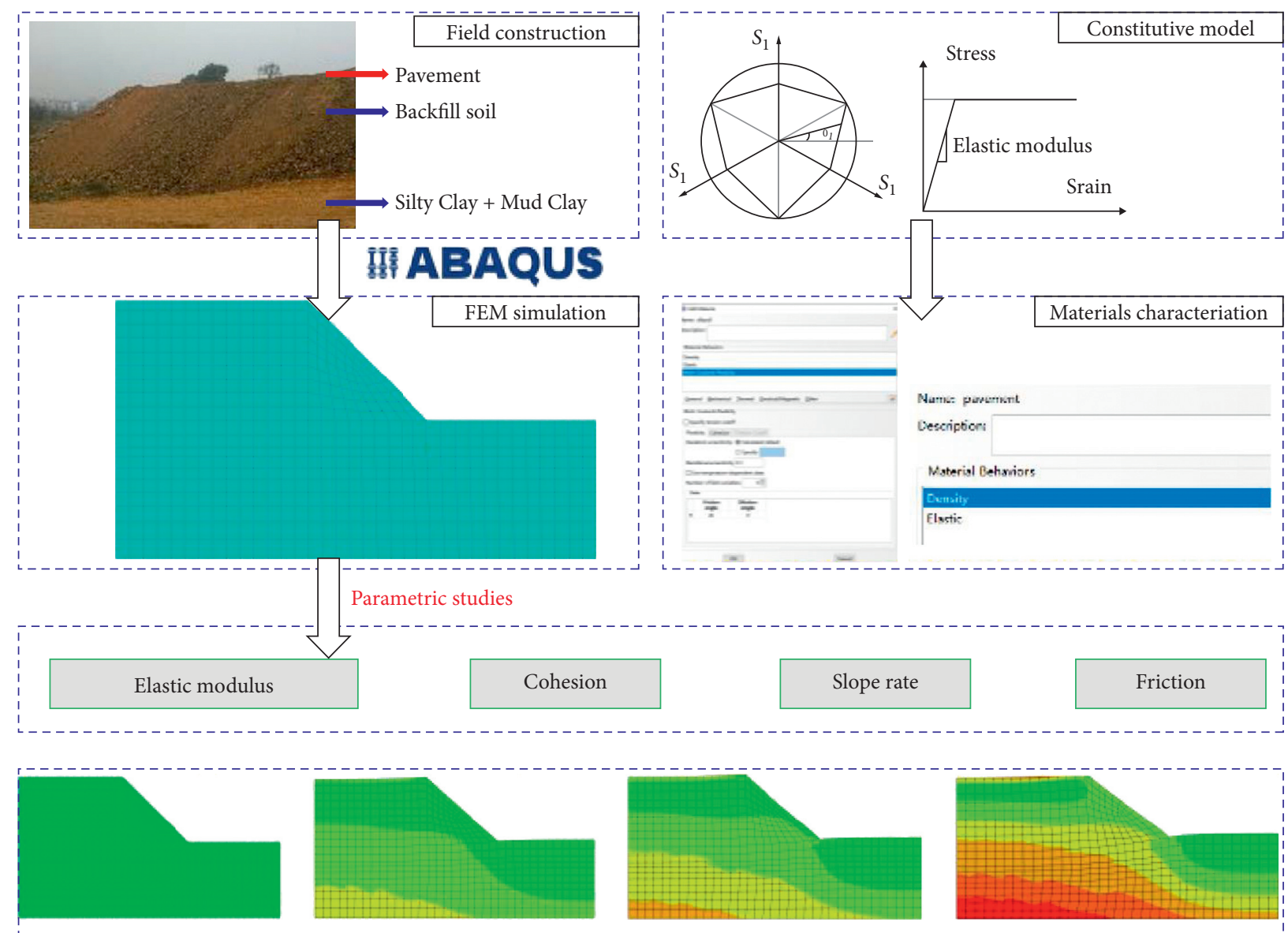

Figure 1: Research objective and overview.

will be broken, and the shear strength has a linear relationship with the normal stress acting on the surface. The yield surface equation of the Mohr-Coulomb model $[53,54]$ can be presented as follows:

$$
F=R_{m c} q-p \tan \varphi-c=0,
$$

in which $\varphi\left(\theta, f^{\alpha}\right)$ is the friction angle on the meridian plane; $c\left(\varepsilon^{-p l}, \theta, f^{\alpha}\right)$ represents the changing process of the cohesive force of the material according to the isotropic hardening model. $p$ is the equivalent compressive stress. $q$ is the Mises equivalent stress. $R_{m c}$ is the deviatoric stress coefficient of the Mohr-Coulomb model $[55,56]$, which can be defined as

$$
R_{m c}(\theta, \varphi)=\frac{1}{\sqrt{3 \cos \varphi}} \sin \left(\theta+\frac{\pi}{3}\right)+\frac{1}{3} \cos \left(\theta+\frac{\pi}{3}\right) \tan \phi,
$$

in which $\varphi$ is the bevel angle of the yield surface of the Mohr-Coulomb model on the P-RMCQ plane, and it generally refers to the internal friction angle of the material. $\theta$ is the direction angle of the generalized shear stress.

3.1. Material Properties. Four types of civil engineering materials were adopted in the present simulation [48]. Table 1 gives the material properties.
The bounding and unbound pavement materials (including the surface layer, base layer, and subbase layer) were simplified to one type of material property [57]. Elastic behavior without plastic deformation characterized by Young's modulus and Poisson's ratio was adopted for the pavement materials. The density of the backfill soil was determined as $1800 \mathrm{~kg} / \mathrm{m}^{3}$. Regarding the Mohr-Coulomb parameters of the backfill soil, the cohesion was determined as 15,20 , and $25 \mathrm{kPa}$, respectively. The internal friction angle was selected as $25^{\circ}$ and $30^{\circ}$, and two elastic moduli of $50 \mathrm{MPa}$ and $100 \mathrm{MPa}$ were determined. The foundation with the lower bearing capacity was characterized by silty clay and mud clay [48]. The corresponding Mohr-Coulomb parameters are shown in Table 1 as well.

3.2. Physical Size of the Whole Model. Figure 2 gives the physical size of the whole model, including the pavement, subgraded by the backfill soil, and the foundation with lower bearing capacity [48].

These physical sizes were determined according to earlier studies [36-42]. The slope angle $\alpha$ is an important parameter considered in the present study, and it varied for different values $(\tan \alpha=1: 1 ; 1: 1.25 ; 1: 1.5 ; 1: 1.75 ; 1: 2)$ to evaluate the effects on the slope stability. To reduce computations, only half of the high-filled subgrade FEM model (symmetric model) was constructed. The width of the pavement was 
TABLE 1: Material properties.

\begin{tabular}{lccccc}
\hline Materials & Density, $\rho\left(\mathrm{kg} / \mathrm{m}^{3}\right)$ & Cohesion, $c(\mathrm{kPa})$ & Internal friction angle, $\varphi\left({ }^{\circ}\right)$ & Elastic modulus, $E(\mathrm{MPa})$ & Poisson's ratio, $\mu$ \\
\hline Pavement materials & 2100 & - & - & 1200 & 0.35 \\
Backfill soil & 1800 & 15,20 , and 25 & 25 and 30 & $40,60,80$, and 100 & 0.35 \\
Silty clay & 1750 & 14 & 22 & 45 & 0.4 \\
Mud clay & 1700 & 12 & 20 & 40 & 0.45 \\
\hline
\end{tabular}

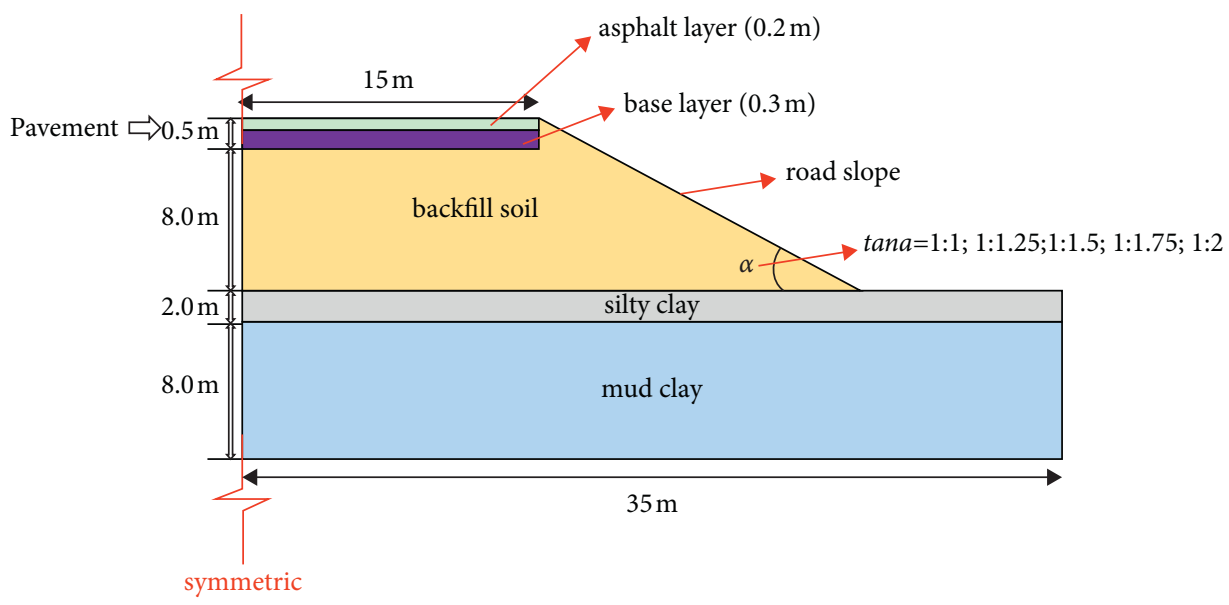

FIGURE 2: High-filled road with the backfill soil.

selected as $15 \mathrm{~m}$ according to the design of the conventional highway. The length of the foundation was determined as $35 \mathrm{~m}$ to support the subgrade by the backfill soil. The dimension of the FE model in the longitudinal direction can be regarded as infinite since only the $2 \mathrm{D}$ model was employed in this study. Under such conditions, the cross section of the road structure was regarded as the research object of the study, and the longitudinal length of the road structure was considered infinite [48].

3.3. Meshing and Element Selection. Figure 3 gives the FE meshing for different slopes used in the present study.

Element selection is the foundation for the FE analysis. For the same FE model, different calculation results can be obtained by using different elements. Regarding the FE model in the present study, the solid element was the optimized one to simulate one part of the whole model. Since a solid element can be connected to other elements through any of its surfaces, it can construct almost any shape and bear any load in the FE model.

To reduce the computations and improve the calculating accuracy, the 8-node plane-strain-reduced (CPE8R) element was adopted in the present FE simulation. It is a general plane strain element, in fact, a special plane stress element, which can be used to simulate a section of a very long structure, such as a dam. It is understood that the plate or shell element may be more efficient to solve the plane strain problem considering the high efficiency during the application. However, it should be noted that the research objective in the present study is about the subgrade and road pavement, which are not satisfying the premise of plate or shell theory. Therefore, the solid element, CPE8R, was employed in the present study. Also, it should be noted that the structure containing the plane strain element should be defined in the global $X-Y$ plane, that is, for all nodes $z=0$.

\section{Parametric Studies}

4.1. Effects of Slope Angle. The soil was defined by the Mohr-Coulomb model, which is the so-called rigid plastic model or Saint-Venant model. Regarding the Mohr-Coulomb model, when the stress of the soil is less than the yield stress, the soil will not deform, just like a rigid body. When the stress reaches the soil yield stress, the plastic deformation will increase until the soil failure occurs. Therefore, the equivalent plastic strain (PEEQ) should be evaluated first, considering the proposed models. Figure 4 gives the results of PEEQ when the slopes are $1: 1,1: 1.25,1$ : $1.5,1: 1.75$, and $1: 2$, respectively.

As shown in Figure 4, under the conditions of a given strength reduction coefficient, the calculation results obtained through the FE simulation can show the development of the equivalent plastic zone in the form of cloud diagrams. When the slopes were $1: 5,1: 1.75$, and $1: 2$, respectively, failure to achieve penetration or local yield failure indicates that the slope is stable under this reduction factor, while when the slopes equal $1: 1.25$ and $1: 1$, the plastic deformation between adjacent iteration steps at some nodes increases too much or the equivalent plastic strain reaches the yield limit. From the displayed results (Figure 4), the plastic zone has penetrated the top of the slope, and the equivalent plastic strain and displacement have an infinite development trend, with obvious sudden changes, indicating that the slope is already in a critical failure state at this time. 


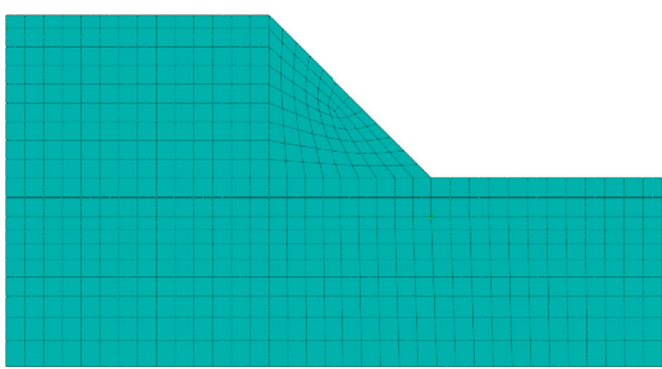

(1) slope $=1: 1$

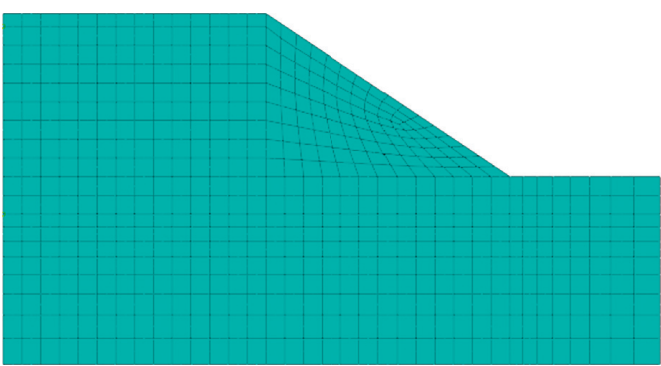

(3) slope $=1: 1.5$

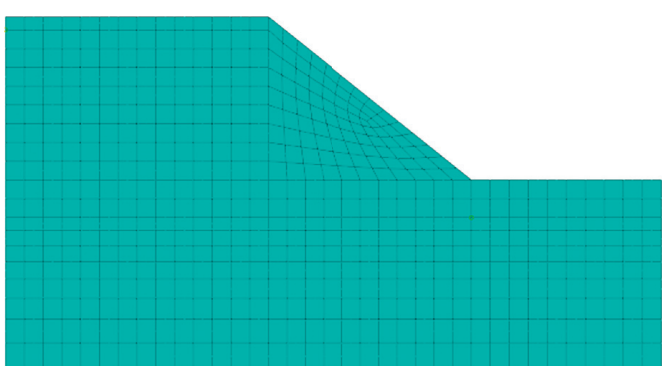

(2) slope $=1: 1.25$

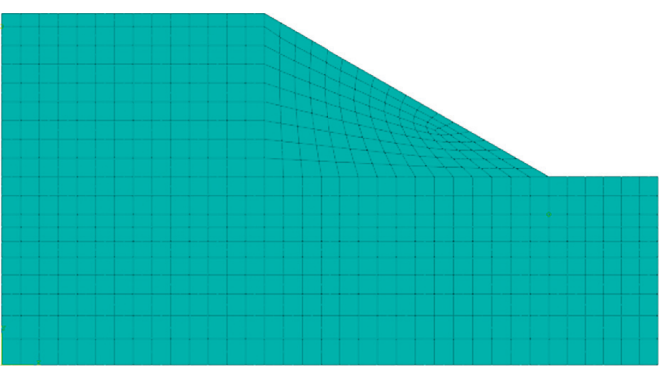

(4) slope $=1: 1.75$

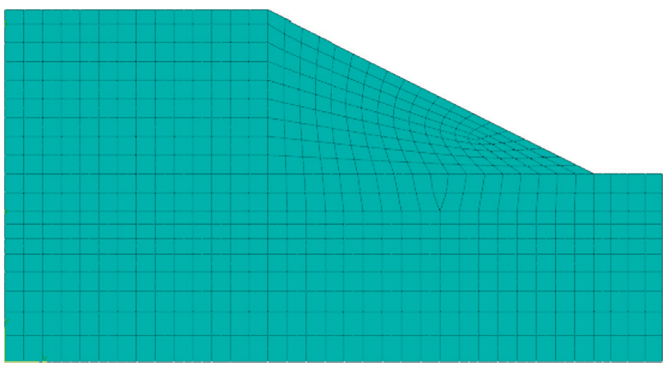

(5) slope $=1: 2$

Figure 3: FEM meshes for the five types of slopes. (a) Slope $=1: 1$. (b) Slope $=1: 1.25$. (c) Slope $=1: 1.5$. (d) Slope $=1: 1.75$. (e) Slope $=1: 2$.

Also, it can be observed that when the slopes are 1:1, 1: $1.25,1: 1.5,1: 1.75$, and $1: 2$, the maximum PEEQ are $1.058 e-2,9.026 e-3,8.999 e-3,6.556 e-3$, and 6.807e-3. Basically, as the slope decreases, the maximum PEEQ decreases, as shown in Figure 4. It can be indicated that reducing the slope can improve the stability of the road slope. Also, it can be observed that when the slope is lower than $1: 1.75$, the maximum PEEQ tends to converge.

4.2. Effects of Cohesion and Internal Friction Angle. It can be observed that, as the cohesion equals $15 \mathrm{kPa}$, the maximum PEEQ for internal friction angles $25^{\circ}$ and $30^{\circ}$ are $1.058 \times 10^{-2}$ and $1.022 \times 10^{-2}$, respectively. A higher internal friction angle can increase the value of maximum PEEQ. As the cohesion equals $20 \mathrm{kPa}$, the maximum PEEQ when the internal friction angles equal $25^{\circ}$ and $30^{\circ}$ are $1.019 \times 10^{-2}$ and $1.023 \times 10^{-2}$, respectively. However, as the cohesion increases to $30 \mathrm{kPa}$, the maximum PEEQ when the internal friction angles equal $25^{\circ}$ and $30^{\circ}$ are still $1.019 \times 10^{-2}$ and $1.023 \times 10^{-2}$, respectively. This means that, as the internal friction angles equal $25^{\circ}$ and $30^{\circ}$, even the cohesion increases, and the maximum PEEQ will remain the same.
Also, it can be observed that when the internal friction angle equals $25^{\circ}$, the maximum PEEQ when the cohesions equal $15 \mathrm{kPa}, 20 \mathrm{kPa}$, and $30 \mathrm{kPa}$ are $1.058 e^{-2}, 1.019 e^{-2}$, and $1.019 e^{-2}$, respectively. The result proves that $20 \mathrm{kPa}$ is the split point of the maximum PEEQ. When the internal friction angle equals $30^{\circ}$, the maximum PEEQ when the cohesions equal $15 \mathrm{kPa}, 20 \mathrm{kPa}$, and $30 \mathrm{kPa}$ are $1.022 e-2$, $1.023 e-2$, and $1.023 e-2$, respectively. This result can also prove that $20 \mathrm{kPa}$ is the split point of the maximum PEEQ. It can further be observed that the increase rate of the maximum PEEQ between $15 \mathrm{kPa}$ and $20 \mathrm{kPa}$ is very small (about $0.1 \%)$. Therefore, it can conclude that higher cohesion and internal friction angle can decrease the maximum PEEQ, but when the cohesion or internal friction angle is higher than one constant value, the maximum PEEQ will remain the same.

The cohesive force of the backfill has a great influence on the overall stability of the slope. With the increase of the cohesion of the backfill, the safety and stability factor also greatly increases, indicating that when the cohesive force of the subgrade soil is high, the stability of the roadbed slope is also high. It can be seen from Figure 5 that the cohesion is increased by $5 \mathrm{kPa}$, and the stability coefficient can be 


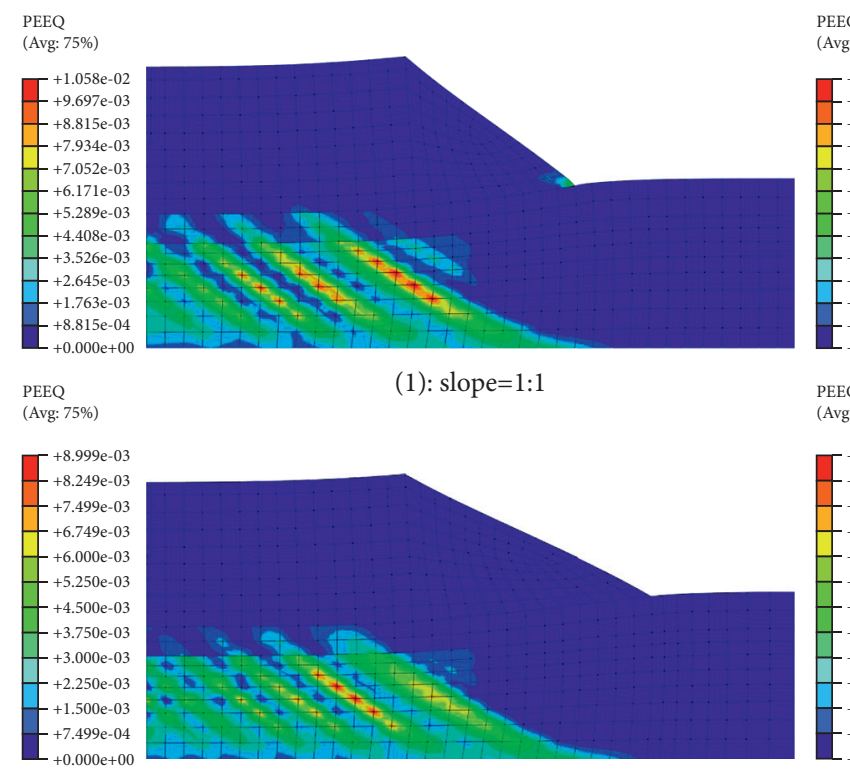

(3): slope $=1: 1.5$

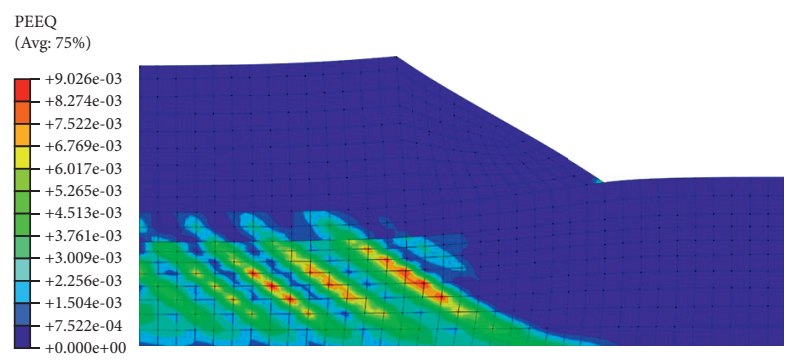

(2): slope $=1: 1.25$

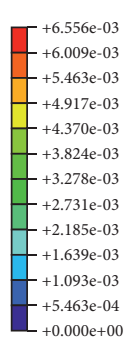

$+0.000 \mathrm{e}+00$

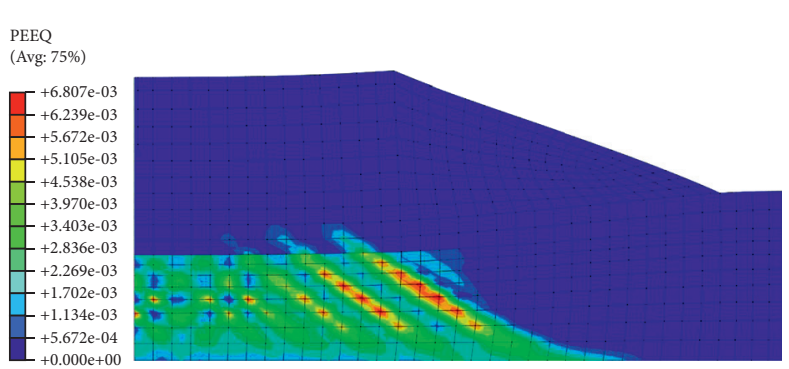

(5): slope $=1: 2$

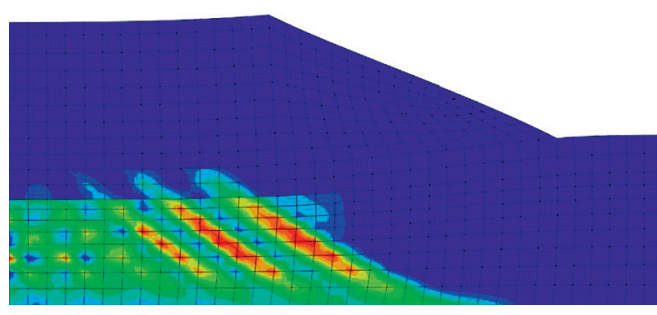

(4): slope $=1: 1.75$

Figure 4: Effects of road slopes on PEEQ. (a) Slope $=1: 1$. (b) Slope $=1: 1.25$. (c) Slope $=1: 1.5$. (d) Slope $=1: 1.75$. (e) Slope $=1: 2$.

increased by about $10 \%$. When the cohesion is large, the contribution to the safety and stability coefficient gradually decreases. It can also be seen that if the backfill material with greater cohesion is selected, the stability of the roadbed slope can be significantly improved. The safety and stability factor remains unchanged as the cohesive force of the weak foundation changes. The main reason may be related to the high fill height of the roadbed. Because when the height of the roadbed is large, the additional stress generated by the external load has a limited range, that is, the working area of the roadbed does not penetrate deep into the soil foundation, the influence of the change of the soil foundation material parameters on the results can be almost ignored. Through the above analysis, we can know the importance of subgrade soil cohesion in highway engineering, and foundation cohesion has little effect on stability.

4.3. Effects of Elastic Modulus. According to the strength reduction theory, when the finite element calculation does not converge due to the reduction of strength parameters, the slope shear failure occurs. Therefore, the reduction coefficient of the strength parameter corresponding to the last convergence calculation can be defined as the safety coefficient of the slope. Based on this determination criterion, Figure 6 gives the relationship between the elastic modulus and safety coefficient when the cohesion and internal friction angle equal $15 \mathrm{kPa}$ and $25^{\circ}$, respectively.

It can be found from Figure 6 that the elastic modulus of the backfill soil has little effect on the safety and stability coefficient of the slope. In the case of a lower modulus of elasticity, the safety and stability coefficient of the slope is higher than that of the high modulus of elasticity. The possible reason is that the plastic expansion zone is generated, and when the elastic modulus of the subgrade that occupies most of the entire embankment is small, the overall settlement displacement of the structure increases, which causes the center of gravity of the plastic zone to decrease, which will reduce the sliding force. On the contrary, the safety and stability coefficient of the slope is increased, and this kind of situation cannot be attributed to the improvement of the safety and stability of the slope.

Figure 7 gives the safety coefficients of the road slope for varying cohesion and internal friction angle.

The slight effect of the elastic modulus on the safety coefficient of the road slope can also be found since the slope safety coefficients were almost the same for different elastic moduli. However, it should be noted that the slope safety coefficient was obviously improved when the internal friction angle increased from $25^{\circ}$ to $30^{\circ}$. The internal friction angle is the representative of the internal friction of the soil, 


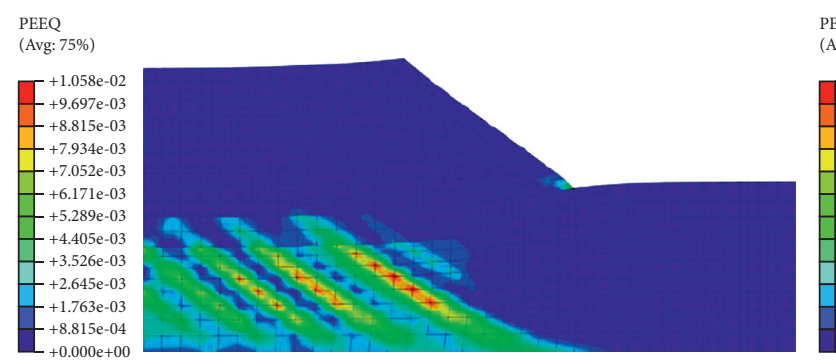

(1) $25^{\circ}-15 \mathrm{kPa}$ PEEQ
(Avg: $75 \%)$

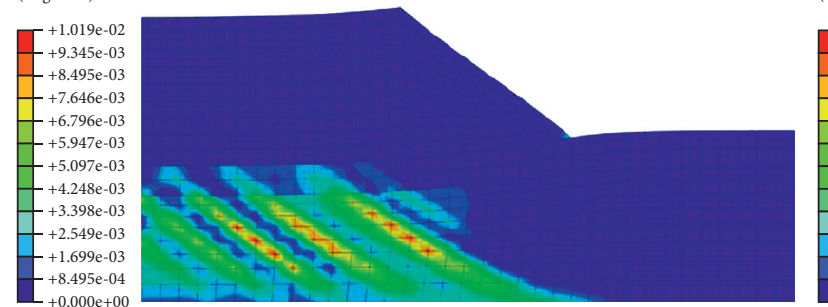

(3) $25^{\circ}-20 \mathrm{kPa}$

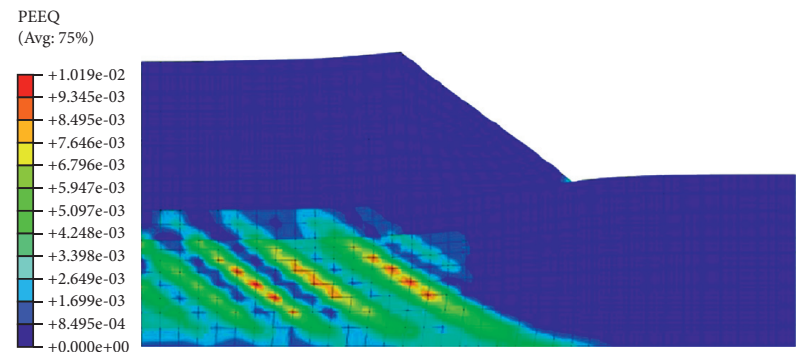

(5) $25^{\circ}-30 \mathrm{kPa}$

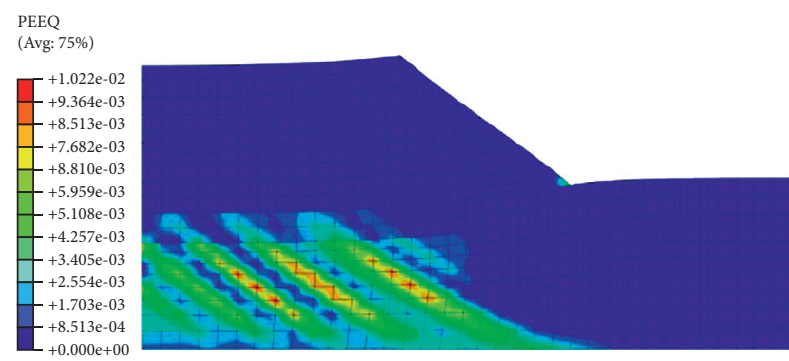

(2) $30^{\circ}-15 \mathrm{kPa}$

PEEQ

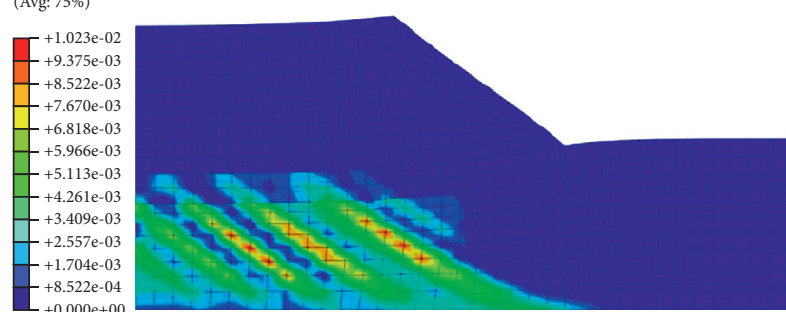

(4) $30^{\circ}-20 \mathrm{kPa}$

PEEQ

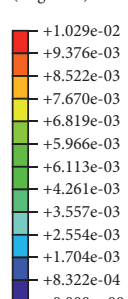

$+8.322 \mathrm{e}-04$

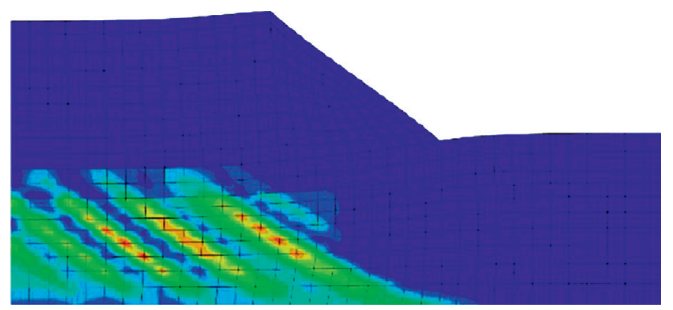

(6) $30^{\circ}-30 \mathrm{kPa}$

FIGURE 5: Effects of cohesion and internal friction angle. (a) $25^{\circ}-15 \mathrm{kPa}$. (b) $30^{\circ}-15 \mathrm{kPa}$. (c) $25^{\circ}-20 \mathrm{kPa}$. (d) $30^{\circ}-20 \mathrm{kPa}$. (e) $25^{\circ}-30 \mathrm{kPa}$. (f) $30^{\circ}$ $30 \mathrm{kPa}$.

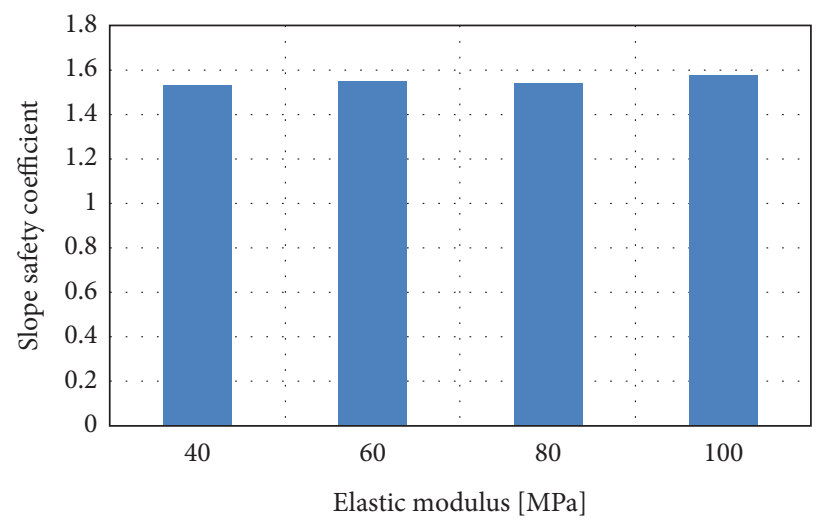

FIGURE 6: Relationship between the elastic modulus and safety coefficient $\left(c=15 \mathrm{kPa} ; \varphi=25^{\circ}\right)$.

which specifically includes the surface friction between the soil particles and the bite force generated by the interlocking action between the soil particles. The larger the internal friction angle, the greater the internal friction force, so as the internal friction angle increases, the maximum equivalent plastic strain value becomes smaller, resulting in a higher value of the slope safety factor.
Figure 8 gives the safety coefficients of the road slope when the cohesion was $15 \mathrm{kPa}$ and $20 \mathrm{kPa}$, respectively.

A slight effect of the elastic modulus on the safety coefficient of the road slope can also be found because of the similar values of slope coefficients. Besides, the cohesion increased the values of the slope safety coefficient. Various physical and chemical forces between soil particles 


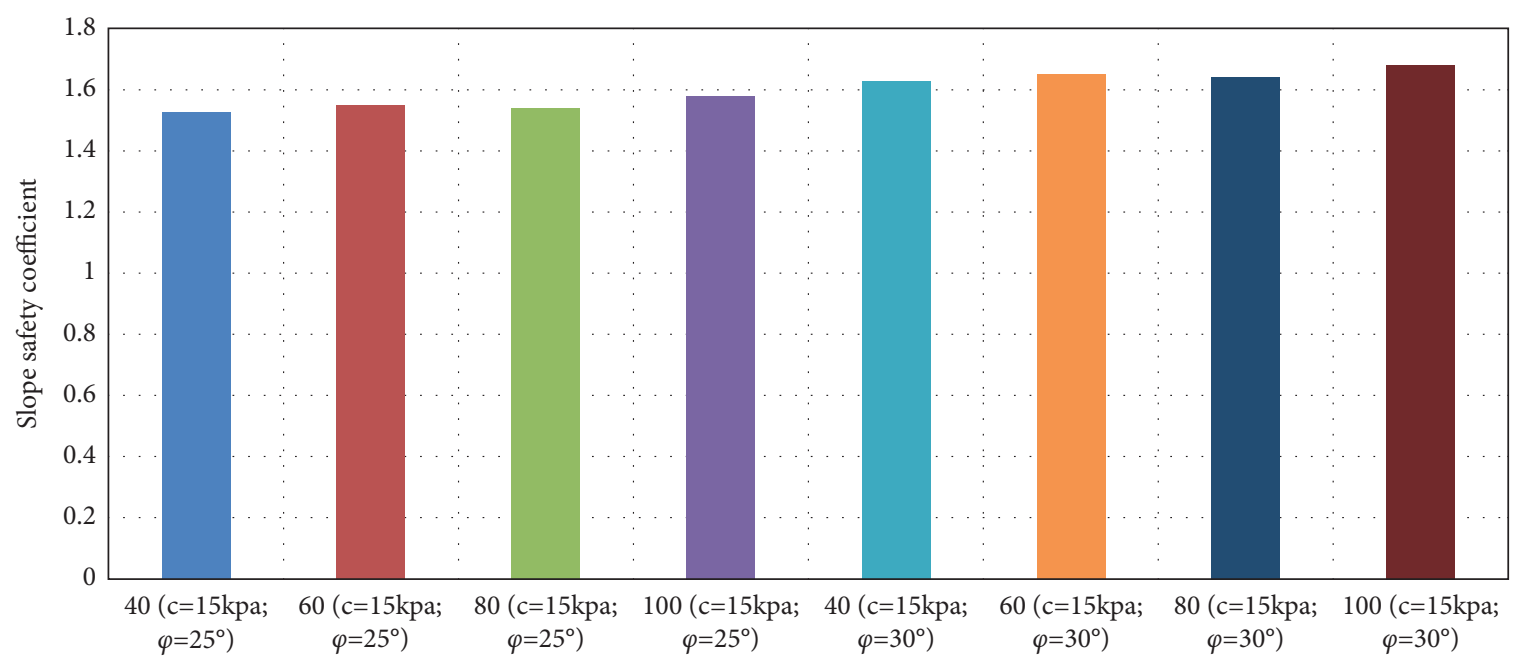

Elastic modulus [MPa]

FIGURE 7: Safety coefficients of the road slope for varying cohesion and internal friction angle.

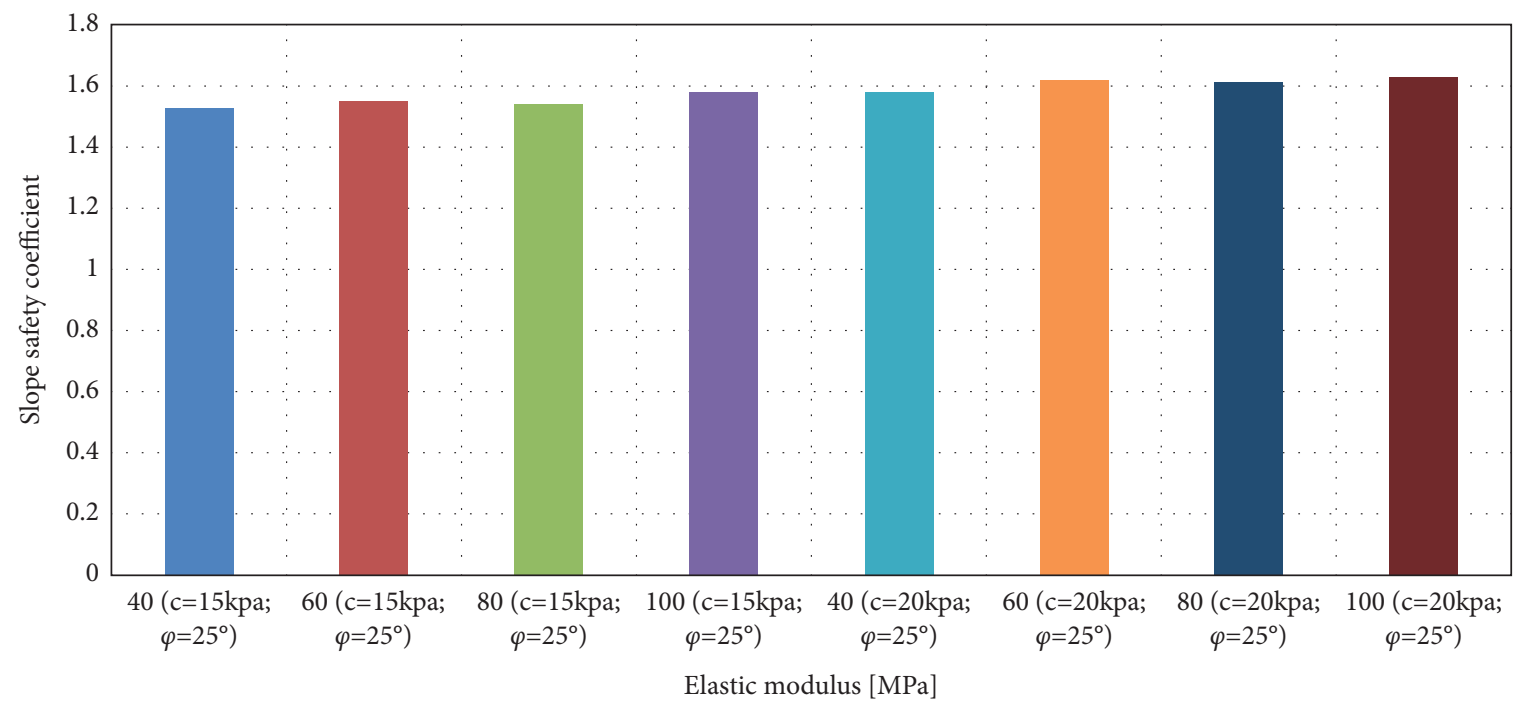

FIgURE 8: Safety coefficients of the road slope when the cohesion was $15 \mathrm{kPa}$ and $20 \mathrm{kPa}$.

determine the value of soil cohesion, including Coulomb force, static force, van der Waals force, and cementation. The greater the cohesive force, the greater the suction force between the particles so that only when the external force is given greater pulling force can plastic strain occur, and the corresponding antisliding force is greater.

\section{Conclusions}

According to the current construction requirements of the process of backfilling the subgrade on the weak foundation, this paper conducted a FE analysis on the slope of this special engineering condition based on the commonly used strength reduction method in the stability analysis of the road slope. To accurately investigate the influence of slope and the mechanical properties of the soil on the stability of the backfill subgrade during the construction process, the slope stability model based on the strength reduction method is established in this study. At the same time, the influence analysis of the slope, cohesion, and internal friction angle on the slope stability was carried out. The research process can highlight the following conclusions:

(1) The slope stability analysis model established by the strength reduction method can characterize the stability of the slope by calculating the slope safety coefficient. In the analysis process, the mutation point of the relationship curve between the displacement generated in the slope and the reduction coefficient is used as the criterion.

(2) As the slopes were lower than $1: 1.5$, failure to achieve penetration or local yield failure indicates that the slope is stable under this reduction factor, while as the slopes were higher than $1: 1.5$, the plastic 
zone has penetrated the top of the slope, and the equivalent plastic strain and displacement have an infinite development trend, indicating a critical failure state. As the slope decreases, the maximum PEEQ decreases; reducing the slope can improve the stability of the road slope. When the slope is lower than $1: 1.75$, the maximum PEEQ tends to converge. Higher values of internal friction angle and cohesion can increase the value of maximum PEEQ, but when the cohesion or internal friction angle is higher than one constant value, the maximum PEEQ will remain the same. The effects of the elastic modulus of the backfill soil on the safety and stability coefficient of the slope are slight.

Regarding future development, a more precise 3D FEM model should be proposed by considering the dimensional sizes in the longitudinal direction. The reasonable physical sizes of the FEM model should also be optimized and determined in the future. Comparison results between the $2 \mathrm{D}$ and 3D models should also be included to evaluate the accuracy and efficiency.

\section{Data Availability}

The data used to support the findings of this study are available from the corresponding author upon request.

\section{Conflicts of Interest}

The authors declare that they have no conflicts of interest to report regarding the present study.

\section{Acknowledgments}

This research was funded by the Faculty Start-up Grant of China University of Mining and Technology (Grant no. 102520282) and the Natural Science Foundation of Jiangsu Province (Grant no. BK20210513).

\section{References}

[1] A. W. Bishop, "The use of the slip circle in the stability analysis of slopes," Géotechnique, vol. 5, no. 1, pp. 7-17, 1955.

[2] Y. Sebsadji, S. Glaser, S. Mammar, and J. Dakhlallah, "Road slope and vehicle dynamics estimation," in Proceedings of the 2008 American Control Conference, June 2008.

[3] P. Lingman and B. Schmidtbauer, "Road slope and vehicle mass estimation using Kalman filtering," Vehicle System Dynamics, vol. 37, no. sup1, pp. 12-23, 2002.

[4] H. Ohnishi, J. Ishii, M. Kayano, and H. Katayama, "A study on road slope estimation for automatic transmission control," JSAE Review, vol. 21, no. 2, pp. 235-240, 2000.

[5] J. Huang, T. Duan, Y. Lei, and M. Hasanipanah, "Finite element modeling for the antivibration pavement used to improve the slope stability of the open-pit mine," Shock and Vibration, vol. 2020, Article ID 6650780, 11 pages, 2020.

[6] W. Shan, C. C. Zhang, and Y. Guo, "Mechanism of shallow slide on soil road cutting slope during spring in seasonal frozen region," Applied Mechanics and Materials, Trans Tech Publication, Bäch SZ, Switzerland, 2012.
[7] J. Huang, Y. Sun, and J. Zhang, "Reduction of computational error by optimizing SVR kernel coefficients to simulate concrete compressive strength through the use of a human learning optimization algorithm," Engineering with Computers, vol. 37, 2021.

[8] F. J. Swanson and C. T. Dyrness, "Impact of clear-cutting and road construction on soil erosion by landslides in the western Cascade Range, Oregon," Geology, vol. 3, no. 7, pp. 393-396, 1975.

[9] D. Tarchi, G. Antonello, N. Casagli, and P. Farina, On the Use of Ground-Based SAR Interferometry for Slope Failure Early Warning: The Cortenova Rock Slide (Italy), pp. 337-342, Springer, New York USA, 2005.

[10] J. Huang, J. Zhang, J. Ren, and H. Chen, “Anti-rutting performance of the damping asphalt mixtures (DAMs) made with a high content of asphalt rubber (AR)," Construction and Building Materials, vol. 271, Article ID 121878, 2021.

[11] H. Luo, T. Zhao, M. Dong et al., "Field studies on the effects of three geotextiles on runoff and erosion of road slope in Beijing, China," Catena, vol. 109, pp. 150-156, 2013.

[12] J. L. Clayton, Evaluating Slope Stability Prior To Road Construction, Vol. 307, US Department of Agriculture, Forest Service, Intermountain Forest and Range, , Ogden, UT, USA, 1983.

[13] J. Huang, M. Losa, P. Leandri, S. G. Kumar, J. Zhang, and Y. Sun, "Potential anti-vibration pavements with damping layer: finite element (FE) modeling, validation, and parametrical studies," Construction and Building Materials, vol. 281, Article ID 122550, 2021.

[14] Z. Cai and X. Zheng, "A private and efficient mechanism for data uploading in smart cyber-physical systems," IEEE Transactions on Network Science and Engineering, vol. 7, no. 2, pp. 766-775, 2018.

[15] D. Nash, "A comparative review of limit equilibrium methods of stability analysis," Slope stability, pp. 11-75, 1987.

[16] W. Verhaeghe, W. Desmet, D. Vandepitte, and D. Moens, "Interval fields to represent uncertainty on the output side of a static FE analysis," Computer Methods in Applied Mechanics and Engineering, vol. 260, pp. 50-62, 2013.

[17] R. Ibrahim and C. Pettit, "Uncertainties and dynamic problems of bolted joints and other fasteners," Journal of Sound and Vibration, vol. 279, no. 3-5, pp. 857-936, 2005.

[18] G. S. Kumar and S. Suresha, "Evaluation of workability and mechanical properties of nonfoaming warm mix asphalt mixtures," Advances in Civil Engineering Materials, vol. 7, no. 1, pp. 132-157, 2018.

[19] P. W. Mayne, "Stress-strain-strength-flow parameters from enhanced in-situ tests," in Proceedings of the International Conference On in Situ Measurement of Soil Properties and Case Histories, Bali, Indonesia, May 2001.

[20] K. Senneset and N. Janbu, "Shear strength parameters obtained from static cone penetration tests," Strength Testing of Marine Sediments: Laboratory and In-Situ Measurements, ASTM International, West Conshohocken, PA, USA, 1985.

[21] S. M. Olson and T. D. Stark, "Yield strength ratio and liquefaction analysis of slopes and embankments," Journal of Geotechnical and Geoenvironmental Engineering, vol. 129, no. 8, pp. 727-737, 2003.

[22] J. Huang, T. Duan, Y. Zhang, J. Liu, J. Zhang, and Y. Lei, "Predicting the permeability of pervious concrete based on the beetle antennae search algorithm and random forest model," Advances in Civil Engineering, vol. 2020, Article ID 8863181, 11 pages, 2020. 
[23] W. Wei, Y. M. Cheng, and L. Li, "Three-dimensional slope failure analysis by the strength reduction and limit equilibrium methods," Computers and Geotechnics, vol. 36, no. 1-2, pp. 70-80, 2009.

[24] M. Prokurov, A. Indykin, and A. Alekseytsev, "Increasing the reliability of the soil slopes design using evolutionary modelling," MATEC Web of Conferences, vol. 251, no. 3, Article ID 04017, 2018.

[25] J. T. Christian, C. C. Ladd, and G. B. Baecher, "Reliability applied to slope stability analysis," Journal of Geotechnical Engineering, vol. 120, no. 12, pp. 2180-2207, 1994.

[26] C. H. Juang, Y.-Y. Jhi, and D.-H. Lee, "Stability analysis of existing slopes considering uncertainty," Engineering Geology, vol. 49, no. 2, pp. 111-122, 1998.

[27] B. Yang, X. Li, Y. Hou et al., "Non-invasive (non-contact) measurements of human thermal physiology signals and thermal comfort/discomfort poses-a review," Energy and Buildings, vol. 224, Article ID 110261, 2020.

[28] S. Xie, Z. Yu, and Z. Lv, "Multi-disease prediction based on deep learning: a survey," Computer Modeling in Engineering and Sciences, vol. 127, no. 3, pp. 1-34, 2021.

[29] Z. Wan, Y. Dong, Z. Yu, H. Lv, and Z. Lv, "Semi-supervised support vector machine for digital twins based brain image fusion," Frontiers in Neuroscience, vol. 15, p. 802, 2021.

[30] Z. Lv, S. Zhang, and W. Xiu, "Solving the security problem of intelligent transportation system with deep learning," IEEE Transactions on Intelligent Transportation Systems, vol. 22, no. 7, pp. 1-10, 2020.

[31] Z. Lv, L. Qiao, K. Cai, and Q. Wang, "Big data analysis technology for electric vehicle networks in smart cities," IEEE Transactions on Intelligent Transportation Systems, vol. 22, no. 3, pp. 1-10, 2020.

[32] M. Jahanbakht, W. Xiang, L. Hanzo, and M. R. Azghadi, "Internet of underwater Things and big marine data analytics-a comprehensive survey," IEEE Communications Surveys \& Tutorials, vol. 23, pp. 904-956, 2021.

[33] X. Cheng, B. Yang, A. Hedman, T. Olofsson, H. Li, and L. G. Van, "NIDL: a pilot study of contactless measurement of skin temperature for intelligent building," Energy and Buildings, vol. 198, pp. 340-352, 2019.

[34] Z. Cai and Z. He, "Trading private range counting over big IoT data," in Proceedings of the 2019 IEEE 39th International Conference on Distributed Computing Systems (ICDCS), July 2019.

[35] M. Hudson, I. Idriss, and M. Beikae, User's Manual for QUAD4M: A Computer Program to Evaluate the Seismic Response of Soil Structures Using Finite Element Procedures and Incorporating a Compliant Base, University of California, Los Angeles, CA, USA, 1994.

[36] J. Huang, X. Li, J. Zhang, Y. Sun, and J. Ren, "Determining the Rayleigh damping parameters of flexible pavements for finite element modeling," Journal of Vibration and Control, vol. 27, 2021.

[37] J. Huang, T. Duan, Y. Sun, L. Wang, and Y. Lei, "Finite element (FE) modeling of indirect tension to cylindrical (ITCY) specimen test for damping asphalt mixtures (DAMs)," Advances in Civil Engineering, vol. 2020, Article ID 6694180, 11 pages, 2020.

[38] A. Hamim, N. I. M. Yusoff, H. Ceylan, S. A. P. Rosyidi, and A. El-Shafie, "Comparative study on using static and dynamic finite element models to develop FWD measurement on flexible pavement structures," Construction and Building Materials, vol. 176, pp. 583-592, 2018.
[39] O. E. Gungor, I. L. Al-Qadi, A. Gamez, and J. A. Hernandez, "In-situ validation of three-dimensional pavement finite element models," The Roles of Accelerated Pavement Testing in Pavement Sustainability, Springer, Berlin, Germany, pp. 145-159, 2016.

[40] J. Fu, J. Liu, X. Zhang, L. Lei, X. Ma, and Z. Liu, "Mesoscale experimental procedure and finite element analysis for an indirect tensile test of asphalt concrete," Road Materials and Pavement Design, vol. 19, no. 8, pp. 1904-1925, 2018.

[41] J. M. Duncan, "State of the art: limit equilibrium and finiteelement analysis of slopes," Journal of Geotechnical engineering, vol. 122, no. 7, pp. 577-596, 1996.

[42] D. Deb and K. C. Das, "A new doubly enriched finite element for modelling grouted bolt crossed by rock joint," International Journal of Rock Mechanics and Mining Sciences, vol. 70, pp. 47-58, 2014.

[43] K.-J. Bathe, Finite Element Procedures, Klaus-Jurgen Bathe, Berlin, Germany, 2006.

[44] K. P. Aryal, "Slope stability evaluations by limit equilibrium and finite element methods," Norwegian University of Science and Technology, Trondheim, Norway, 2006.

[45] M. Ameri, M. Malakouti, and P. Malekzadeh, "Quasi-static analysis of multilayered domains with viscoelastic layer using incremental-layerwise finite element method," Mechanics of Time-Dependent Materials, vol. 18, no. 1, pp. 275-291, 2014.

[46] A. Ardah, M. Abu-Farsakh, and G. Voyiadjis, "Numerical evaluation of the performance of a geosynthetic reinforced soil-integrated bridge system (GRS-IBS) under different loading conditions," Geotextiles and Geomembranes, vol. 45, no. 6, pp. 558-569, 2017.

[47] G. You, M. A. Mandalawi, A. Soliman, and K. Dowling, "Finite element analysis of rock slope stability using shear strength reduction method," in Proceedings of the International Congress and Exhibition Sustainable Civil Infrastructures: Innovative Infrastructure Geotechnology, July 2017.

[48] H. L. Gongyun, Application of Finite Element Software ABAQUS on Road Engineering, Southeast University Press, Nanjing, China, 2008.

[49] Z. Yingren and Z. Shangyi, "Application of strength reduction FEM in soil and rock slope," Chinese Journal of Rock Mechanics and Engineering, vol. 19, p. 37, 2004.

[50] S. Y. Zhao, Y. R. Zheng, and Y. F. Zhang, "Study on slope failure criterion in strength reduction finite element method," Rock and Soil Mechanics, vol. 2, pp. 332-336, 2005.

[51] A. S. Genikomsou and M. A. Polak, "Finite element analysis of punching shear of concrete slabs using damaged plasticity model in ABAQUS," Engineering Structures, vol. 98, pp. 3848, 2015.

[52] E. Duni, G. Monfrino, R. Saponaro et al., "Numerical simulation of full vehicle dynamic behaviour based on the interaction between ABAQUS/standard and explicit codes," in Proceedings of the Abaqus Users' Conference, Munich, Germany, June 2003.

[53] D. J. Robert, "A modified Mohr-Coulomb model to simulate the behavior of pipelines in unsaturated soils," Computers and Geotechnics, vol. 91, pp. 146-160, 2017.

[54] J. Clausen, L. Damkilde, and L. V. Andersen, "Robust and efficient handling of yield surface discontinuities in elastoplastic finite element calculations," Engineering Computations, vol. 32, no. 6, 2015.

[55] D. A. Lockner and S. A. Stanchits, "Undrained poroelastic response of sandstones to deviatoric stress change," Journal of Geophysical Research: Solid Earth, vol. 107, no. B12, 2002. 
[56] N. Changizi and G. P. Warn, "Stochastic stress-based topology optimization of structural frames based upon the second deviatoric stress invariant," Engineering Structures, vol. 224, Article ID 111186, 2020.

[57] J. Huang, P. Leandri, G. Cuciniello, and M. Losa, "Mix design and laboratory characterisation of rubberised mixture used as damping layer in pavements," International Journal of Pavement Engineering, vol. 22, pp. 1-15, 2021. 